\title{
Aluminium Tolerance Assessment of 141 Maize Germplasms in a Solution Culture
}

\author{
Liming Xu ${ }^{1}$, Wu Liu ${ }^{1}$, Baoming Cui ${ }^{2}$, Ning Wang ${ }^{1}$, Jianzhou Ding ${ }^{1}$, Chan Liu ${ }^{1}$, Shibin Gao ${ }^{1}$, \\ Suzhi Zhang',*

\begin{abstract}
${ }^{1}$ Key Laboratory of Biology and Genetic Improvement of Maize in Southwest China of Agricultural Department, Ministry of Agriculture, Maize Research Institute, Sichuan Agricultural University, China

${ }^{2}$ Crop Research Institute of Binzhou, Huanghe $2^{\text {nd }}$ Road 654, Binzhou 256600, China
\end{abstract}

Copyright $\bigcirc 2017$ by authors, all rights reserved. Authors agree that this article remains permanently open access under the terms of the Creative Commons Attribution License 4.0 International License

\begin{abstract}
Aluminum (Al) toxicity usually occurs in acidic soils with a $\mathrm{pH}$ of 5.5 or lower. The selection and breeding of Al-tolerant cultivars is a useful approach for protecting maize from Al toxicity. Rapid and reliable screening methods must be developed to discriminate Al-tolerant and Al-sensitive maize genotypes. The relative root growth (RRG) of the longest root in a toxic Al solution was used to classify 141 maize germplasm lines into three groups with varied $\mathrm{Al}$ sensitivity: Al-sensitive, moderately Al-tolerant, and Al-tolerant. Among these lines, the cultivars HZ85 and 178 had the highest RRG values and therefore the highest Al tolerance. Further root assessment of six representative lines using other methods, such as digital imaging analysis of total root length and superficial area or volume, biomass measurement, and hematoxylin staining, was roughly consistent with the classification based on RRG. These results indicated that the RRG of the longest root could be used as a reliable and reproducible phenotypic index for the evaluation of $\mathrm{Al}$ tolerance in maize genotypes. Cultivars with different $\mathrm{Al}$ tolerances can be used to improve breeding and explore the mechanism of $\mathrm{Al}$ tolerance in maize.
\end{abstract}

Keywords Maize, Aluminum Toxicity, Phenotypic Index, Digital Imaging, Hematoxylin Staining

\section{Introduction}

Acidic soils, with a $\mathrm{pH}$ of 5.5 or lower, are distributed extensively across the world. Approximately $30 \%$ of the world's total land area and over $50 \%$ of potentially arable lands are acidic, with the majority $(60 \%)$ of this area in the tropics and subtropics [1]. China also has a large amount of acidic soils. Xiong and Li [2] reported that acidic soils are distributed in 14 provinces and occupy up to 2030 thousand $\mathrm{km}^{2}$, or $21 \%$ of cultivated land, in China. Soils acidify very slowly, over hundreds to millions of years, under natural conditions. However, the anthropogenic acidification of soils has received more attention. The overuse of $\mathrm{N}$ fertilizer contributes substantially to regional soil acidification both directly and indirectly [3]. Moreover, acid rain, which contains nitric and sulfuric acids, is increasing the rate of soil acidification in many locations in China [4].

A number of factors contribute to acidic soil toxicity depending on soil composition. In acidic soils with a high mineral nutrition content, the primary factor limiting plant growth is $\mathrm{Al}$ toxicity, which is most serious when soil acidity is below $\mathrm{pH}$ 4.0[5-7]. At low $\mathrm{pH}$ values, toxic forms of $\mathrm{Al}$, such as $\mathrm{Al}(\mathrm{OH})_{2}^{+}, \mathrm{Al}(\mathrm{OH})^{2+}$, and $\mathrm{Al}^{3+}$, are released into the soil solution. For most crops, free $\mathrm{Al}^{3+}$ is the main toxic $\mathrm{Al}$ ion that actively damages root growth, thus affecting the development of the whole plant $[5,8]$. Roots exposed to toxic $\mathrm{Al}$ tend to become short, thick, and underdeveloped, thereby reducing nutrient uptake and increasing susceptibility to environmental stresses [9]. The application of lime in acidic soils can increase the soil $\mathrm{pH}$ and hence reduce the Al toxicity. However, acidity cannot always be corrected in this way due to economic limitations and labor requirements [10]. Furthermore, the heavy application of lime may adversely affect some crops in the rotation or cause deficiencies of certain nutrients.

To relieve the toxicity of Al stress and improve the crop yield in acidic soils, the breeding and cultivation of Al-tolerant crops is a useful alternative approach. The first step in this approach is to select a reliable method for screening numerous crop lines that possess $\mathrm{Al}$ resistance at various levels.

Much effort has been devoted to improving screening methods for $\mathrm{Al}$ tolerance to better identify cultivar differences [11]. The primary screening methods for $\mathrm{Al}$ tolerance include field evaluations, soil or pot assays, and solution culture assays $[4,12,13]$. Molecular marker-assisted selection has also been developed to screen Al-tolerant genotypes in barley [14]. Field-based screening 
methods are generally more laborious, time consuming, and expensive, whereas laboratory- and greenhouse-based techniques are becoming more widely employed due to their rapidity, nondestructive nature, and high accuracy. Among these methods, the nutrient solution technique is the preferred choice for most research because it provides easy access to root systems, tight control over nutrient availability and $\mathrm{pH}$, and nondestructive measurement of tolerance [15]. Moreover, the nutrient solution technique is most suitable for determining Al activity and avoids other soil-associated stresses [16].

Several screening criteria have been applied for the evaluation of $\mathrm{Al}$ tolerance in nutrient solution culture. Root growth parameters, including root growth length, volume, superficial area, and biomass, have been used as root tolerance indexes to evaluate genotypes for $\mathrm{Al}$ tolerance [17-19]. Comparing Al tolerance levels in wheat, triticale, and rye by measuring root elongation in Al-containing hydroponic solutions, [20] found that rye had a higher degree of Al tolerance than did the other cereals. Dai et al. [10] evaluated the tolerance of 173 Tibetan wheat landraces to $\mathrm{Al}$ stress using root regeneration length measurements in hydroponic solutions containing Al. Fortunately, tedious manual measurements of root growth length have been replaced by automated methods of digital image analysis; for example, these methods were effective for evaluating the $\mathrm{Al}$ tolerance of sorghum plants after a four-day treatment in nutrient solutions [21]. The volume and superficial area of root systems, which describe the dynamic state of root growth based on digital imaging analysis, are reasonable criteria for measuring the $\mathrm{Al}$ tolerance of genotypes in nutrient solution culture [22]. Other phenotypic parameters, such as the fresh and dry weights of the whole root system used as indexes of root biomass, also have been used for the assessment of germplasm for Al tolerance [23].

In addition, hematoxylin staining of roots, which obtains results quickly and efficiently, is suitable for screening a large segregating population. This method, as originally described by Berezovskii et al. [24], has long been used in applications as diverse as genotypic classification $[25,26]$, genetic characterization $[27,28]$, and selection $[29,30]$.

The above approaches provide many options for evaluating maize genotypes for Al tolerance. Several studies have evaluated $\mathrm{Al}$ tolerance in maize cultivars from distinct ecotypes using the relative root growth (RRG) of the longest root [31, 32] and hematoxylin staining [33]. In the current study, we performed $\mathrm{Al}$ tolerance screening in solution for 141 maize genotypes and classified them into three different groups according to the RRG of the longest root. These results were further confirmed by other methods such as root growth measurement based on digital imaging analysis, whole root biomass measurement, and hematoxylin staining. Finally, we identified maize genotypes with different Al tolerances that may be used in future Al-tolerant breeding strategies.

\section{Materials and Methods}

\subsection{Plant Materials and Al Treatment}

The 144 maize germplasm lines used in this experiment were collected from China. The seeds were surface sterilized with $75 \%$ alcohol for $1 \mathrm{~min}$ and then with $0.1 \% \mathrm{NaClO}(\mathrm{v} / \mathrm{v})$ for $20 \mathrm{~min}$. After being completely washed with flowing water, the seeds were placed on filter papers saturated with distilled water and germinated at $26^{\circ} \mathrm{C}$ for 3 days in the dark. The seedlings were then transferred to a growth chamber and grown at $26^{\circ} \mathrm{C} / 24^{\circ} \mathrm{C}$ (light/dark, $\left.16: 8 \mathrm{~h}\right)$ under a light intensity of $500 \mathrm{mmol}$ photons $\mathrm{m}^{-2} \mathrm{~s}^{-1}$. Before the $\mathrm{Al}$ treatment, the seedlings were first cultured in an aerated 200 $\mu \mathrm{mol} \mathrm{CaCl} 2(\mathrm{pH}=4.0)$ solution for $24 \mathrm{~h}$. Subsequently, these seedlings were further cultured in an aerated solution containing $60 \mu \mathrm{mol} \mathrm{AlCl}$ and $200 \mu \mathrm{mol} \mathrm{CaCl}_{2}(\mathrm{pH}=4.0)$ for 3 days. Seedlings treated in the same way without the addition of $\mathrm{AlCl}_{3}$ to the solution were used as controls.

\subsection{RRG Measurement}

The measurement of root growth length was performed using at least 20 uniform seedlings of each maize line: 10 for the $\mathrm{Al}$ treatment and 10 as controls. The longest root length before (initial root growth (IRG)) and after treatment (final root growth (FRG)) were measured by a flexible ruler. Net root growth (NRG) was calculated as FRG - IRG, and the RRG of each line was determined as $R R G=N R G$ of Al-treated seedlings/NRG of control seedlings. Three replicates were performed for each line for both the Al-treated and control seedlings.

\subsection{Digital Scanning and Dynamic Growth Analysis of Root Systems}

After Al treatment, the seedling root systems of six representative maize lines, 178, HZ85, CA339, 5022(B), B73, and Mo17, were measured using a scanner (Epson Expression $10000 \mathrm{XL}$ ). Data on the total root length, superficial area, and volume were then quantified and analyzed using the digital scanning system. The same measurements were performed on the control seedlings.

\subsection{Measuring the Biomass of Root Systems}

The total root systems of lines 178, HZ85, CA339, 5022(B), B73, and Mo17 were collected individually after treatment with or without $\mathrm{Al}$ for 3 days, as described above. These fresh roots were dried in an oven at $60^{\circ} \mathrm{C}$ for 2 days and weighed before and after drying using a microgram balance.

\subsection{Hematoxylin Staining}

Roots of 3-day-old treated and control seedlings of the six maize lines (178, HZ85, CA339, 5022(B), B73, and Mo17) 
were stained using a modification of the method described by [24]. Roots were exposed to $\mathrm{AlCl}_{3}$ solution for 3 days and then washed for $30 \mathrm{~min}$ in distilled water. After being stained in hematoxylin solution for $20 \mathrm{~min}$, the roots were washed again for another $30 \mathrm{~min}$ in distilled water and then photographed using a digital camera. The stain solution was prepared before the experiment by placing $0.2 \mathrm{~g}$ of hematoxylin and $0.02 \mathrm{~g}$ of $\mathrm{KIO}_{3}$ in $100 \mathrm{ml}$ of water and stirring the solution overnight to dissolve the hematoxylin.

\section{Results}

\subsection{Classification of 141 Maize Genotypes According to RRG}

RRG of the longest root is the most commonly used parameter for estimating $\mathrm{Al}$ tolerance in cereals [31]. According to the RRG of the longest root, all of the tested maize lines were classified into three categories: Al-tolerant ( $R R G>30 \%)$, moderately Al-tolerant $(15 \%<R R G \leq 30 \%)$, and Al-sensitive (RRG $\leq 15 \%)$. Among the 141 maize germplasm lines, 24 were scored as Al-tolerant, 63 as moderately Al-tolerant, and 54 as Al-sensitive (Table 1). The highest Al tolerance was exhibited by line 178, with an RRG > $40 \%$, while 22 lines had an RRG $<10 \%$ and demonstrated the highest sensitivity to Al. Subsequently, two standard lines from each of the three groups were further examined using other methods: the Al-tolerant lines 178 (RRG = $0.4502)$ and HZ85 $(\mathrm{RRG}=0.3833)$, moderately Al-tolerant lines $\mathrm{CA} 339(\mathrm{RRG}=0.2915)$ and $5022(\mathrm{~B})(\mathrm{RRG}=0.2938)$, and Al-sensitive lines B73 $(R R G=0.1329)$ and Mo17 $(R R G$ $=0.1206$ ).

Table 1. Aluminium-tolerant evaluation of 141 maize seedlings based on relative root growth (RRG) of the longest root

\begin{tabular}{|c|c|c|c|c|c|c|c|c|}
\hline $\begin{array}{c}\text { Maize } \\
\text { germplasm }\end{array}$ & RRG & $\begin{array}{l}\text { Sensitivity } \\
\text { to } \mathrm{Al}\end{array}$ & Maize germplasm & RRG & $\begin{array}{c}\text { Sensitivity to } \\
\mathrm{Al}\end{array}$ & Maize germplasm & RRG & $\begin{array}{c}\text { Sensitivity to } \\
\mathrm{Al}\end{array}$ \\
\hline Jin Huang 31 & 0.118 & \multirow{27}{*}{$\begin{array}{c}\mathrm{Al} \\
\text { sensitive }\end{array}$} & Wen Huang & 0.1399 & \multirow{27}{*}{ Al sensitive } & Jin Huang 48 & 0.1503 & \multirow{27}{*}{$\begin{array}{c}\text { moderately } \mathrm{Al} \\
\text { tolerant }\end{array}$} \\
\hline Jin Huang 55 & 0.0644 & & U8112 & 0.0923 & & Jin Huang 49 & 0.1517 & \\
\hline Jin Huang 76 & 0.1382 & & Duo Huang 29 & 0.0277 & & Jin Huang 61 & 0.1508 & \\
\hline P127 & 0.0746 & & Jin Huang 96B & 0.0941 & & Jin Huang 63 & 0.1909 & \\
\hline P137 & 0.096 & & CN962 & 0.0842 & & P140 & 0.1641 & \\
\hline R3 & 0.0974 & & CN165 & 0.1379 & & Shan Dong 8129 & 0.1522 & \\
\hline Zhong Zong & 0.107 & & $\mathrm{CN} 117$ & 0.0828 & & Zhong Zong & 0.2657 & \\
\hline Wei Er 157 & 0.1301 & & 7063 & 0.1405 & & P141 & 0.2297 & \\
\hline $\begin{array}{l}\text { CA8917 } \\
\text { (sticky) }\end{array}$ & 0.0641 & & 08W-SC16 & 0.1294 & & $91041-2$ & 0.1807 & \\
\hline $91041-2$ & 0.0996 & & 08W-SC20-4 & 0.1346 & & $\mathrm{R} 18$ & 0.1693 & \\
\hline Za C546 & 0.1286 & & 08W-SC36 & 0.1144 & & CA091 & 0.2716 & \\
\hline Shen 5003 & 0.0652 & & $\mathrm{CN} 4397$ & 0.0824 & & $\mathrm{CA} 23$ & 0.2189 & \\
\hline K22 & 0.1172 & & 8065 & 0.1458 & & H18 & 0.2755 & \\
\hline Cai 11-8 & 0.0917 & & Chuan 219-1 & 0.1293 & & Duo 16 & 0.2486 & \\
\hline H6 & 0.1428 & & Chuan 273 & 0.1471 & & A513 & 0.2077 & \\
\hline Ji 846 & 0.1048 & & Qi 319 & 0.1385 & & 8129 & 0.1719 & \\
\hline 374 & 0.1079 & & 3189 & 0.1007 & & H10 & 0.252 & \\
\hline CA181 & 0.1316 & & 81565 & 0.0967 & & Jan-87 & 0.2142 & \\
\hline Liao Ju 311 & 0.0652 & & 196 & 0.1013 & & Ji 818 & 0.2974 & \\
\hline Tie 9010 & 0.0934 & & CAL58 & 0.1111 & & C8605-2 & 0.2857 & \\
\hline $706 \mathrm{Fu}$ & 0.1277 & & 653 & 0.1329 & & Shen 5003 & 0.2895 & \\
\hline 7884 & 0.1184 & & K10 & 0.1094 & & Ji 53 & 0.1546 & \\
\hline 8723 & 0.0764 & & $698-4$ & 0.123 & & 4379 & 0.228 & \\
\hline Ye 52106 & 0.1357 & & M14 & 0.1137 & & $200 \mathrm{~B}$ & 0.24 & \\
\hline Q66 & 0.099 & & $\mathrm{~K} 12$ & 0.0227 & & CA042 & 0.1587 & \\
\hline Drought 21 & 0.096 & & Mo17 & 0.1206 & & Feb-48 & 0.1659 & \\
\hline $\mathrm{Ji}(03)$ & 0.064 & & B73 & 0.1329 & & K12 & 0.2254 & \\
\hline
\end{tabular}




\begin{tabular}{|c|c|c|c|c|c|c|c|c|}
\hline $\begin{array}{c}\text { Maize } \\
\text { germplasm }\end{array}$ & RRG & $\begin{array}{c}\text { Sensitivity to } \\
\mathrm{Al}\end{array}$ & $\begin{array}{c}\text { Maize } \\
\text { germplasm }\end{array}$ & RRG & $\begin{array}{c}\text { Sensitivity to } \\
\mathrm{Al}\end{array}$ & Maize germplasm & RRG & $\begin{array}{c}\text { Sensitivity to } \\
\mathrm{Al}\end{array}$ \\
\hline 832 & 0.1724 & & Qi 205 & 0.1818 & \multirow{12}{*}{$\begin{array}{l}\text { moderately } \\
\text { Al tolerant }\end{array}$} & 08W-SC $88-1$ & 0.318 & \multirow{12}{*}{$\mathrm{Al}$ tolerant } \\
\hline 485 & 0.2734 & & Lu 2548 & 0.2827 & & 08W-SC91-1 & 0.32381 & \\
\hline 3141 & 0.1718 & & $\mathrm{X} 178$ & 0.1611 & & 08W-SC93-1 & 0.3412 & \\
\hline Apr-29 & 0.2466 & & Shen 137 & 0.1602 & & 08W-SC95-4 & 0.32 & \\
\hline Zheng 22 & 0.2872 & & 803 & 0.2638 & & 08W-SC119-1 & 0.3771 & \\
\hline Zhong 17 & 0.2524 & & Duo Huang 212 & 0.25 & & 08W-SC127-3 & 0.3439 & \\
\hline Shen 136 & 0.2256 & & 44 & 0.2601 & & 08W-SC128-2 & 0.3571 & \\
\hline Wu 314 & 0.2916 & & Lin Xi 020 & 0.2027 & & 08W-SC136-1 & 0.3636 & \\
\hline Hua 160 & 0.2061 & & B84 & 0.3 & & 515 & 0.3041 & \\
\hline $\mathrm{C} 103$ & 0.1994 & & WF9 & 0.2282 & & Ji 853 & 0.3238 & \\
\hline Nov-38 & 0.1738 & & CA339 & 0.2915 & & HZ85 & 0.3833 & \\
\hline Mo Qun 17 & 0.1971 & & 5022 (B) & 0.2938 & & 178 & 0.4502 & \\
\hline $\begin{array}{c}\text { Zhong Huang } \\
2041220\end{array}$ & 0.2538 & $\begin{array}{l}\text { moderately } \\
\mathrm{Al} \text { tolerant }\end{array}$ & 314 & 0.359 & \multirow{12}{*}{$\mathrm{Al}$ tolerant } & & & \\
\hline Zhong Zi 01 & 0.1697 & & 643 & 0.3381 & & & & \\
\hline CN563 & 0.2296 & & 2548 & 0.3056 & & & & \\
\hline 08W-SC17-1 & 0.1852 & & Chuan 1073-7 & 0.3643 & & & & \\
\hline 08W-SC-23-2 & 0.2572 & & Qi 318 & 0.3585 & & & & \\
\hline 08W-SC35-1 & 0.2104 & & $\mathrm{OH}-43$ & 0.3372 & & & & \\
\hline 08W-SC37 & 0.1674 & & Ji 495 & 0.3369 & & & & \\
\hline $\begin{array}{c}\text { Zhong Huang } \\
68\end{array}$ & 0.2445 & & Lin Xi 2 & 0.3059 & & & & \\
\hline 141 & 0.1538 & & 7922 & 0.3006 & & & & \\
\hline Lin Xi 004102 & 0.1502 & & Drought 23 & 0.3121 & & & & \\
\hline 08W-SC110-1 & 0.2875 & & Mixture 517 & 0.3455 & & $\mathrm{CV} \%$ & 46.8391 & \\
\hline 08W-SC130-1 & 0.2608 & & 598 & 0.3163 & & $\operatorname{LSD}(\mathrm{P}=0.05)$ & 0.0213 & \\
\hline
\end{tabular}

Note: The six representative lines for the three classes were highlighted in black bold.

\subsection{Al Responses of Six Standard Maize Lines Assessed by Digital Imaging Analysis}

Within the first few days of germination, the root systems of maize seedlings are fibrous and produce multiple primary, secondary, and tertiary roots. A root digital imaging system can quantify the total root length, superficial area, and volume of the entire maize root structure. As expected, all of the six maize genotypes showed some degree of root growth inhibition when grown in the solution containing $60 \mu \mathrm{mol}$ $\mathrm{Al}^{3+}$ (Fig. 1). For the Al-tolerant genotypes HZ85 and 178, the total root length after $\mathrm{Al}$ exposure decreased from 17.86 $\mathrm{cm}$ to $7.89 \mathrm{~cm}(55.81 \%)$ and from $15.12 \mathrm{~cm}$ to $9.42 \mathrm{~cm}$ (37.7\%), respectively (Fig. 1a). The moderately Al-tolerant cultivars CA339 and 5022(B) demonstrated significant root growth disturbance, with inhibition levels of $78.95 \%$ and $68.12 \%$, respectively. In the Al-sensitive cultivars Mo17 and B73, the mean total root lengths were severely inhibited, reaching only $12.5 \%$ those of the control plants. These results showed that total root length inhibition generally agreed with the classification of the three maize groups according to RRG data.

The superficial area and volume of the whole root system were effective indexes of the growth and development of the root system as impacted by abiotic stress in the soil.
Exposure of the maize cultivars to a toxic Al solution decreased both superficial area and volume of the whole root system to different degrees (Fig. 1b, c). When subjected to $\mathrm{Al}$, the Al-tolerant cultivars HZ85 and 178 presented only $37.28 \%$ and $46.14 \%$ of the superficial area and $31.28 \%$ and $41 \%$ of the volume, respectively, of the control plants. For the moderately Al-tolerant cultivars CA339 and 5022(B), both the superficial area and volume of whole root system were dramatically reduced, reaching less than $20 \%$ those of the control plants. Similar results were also observed for the Al-sensitive cultivars B73 and Mo17, which exhibited even more severe $\mathrm{Al}$ inhibition of the superficial area and volume of the whole root system. As can also be seen in the chart (Fig. 1b, c), the data obtained for the superficial area and volume of the whole root systems again indicated that the $\mathrm{Al}$ responses of the six maize cultivars were in accordance with the classifications based on the RRG of the longest root measurement.

Further evaluation revealed that the RRG values positively correlated with the total root length, superficial area, and volume of the entire maize root. The correlation relation analysis shows that the correlation coefficients between the RRG of the seminal root and the root length was moderate $(\mathrm{r}=0.53)$ while that between the RRG and the root superficial area $(\mathrm{r}=0.12)$ or root volume $(\mathrm{r}=0.21)$ was weak. 

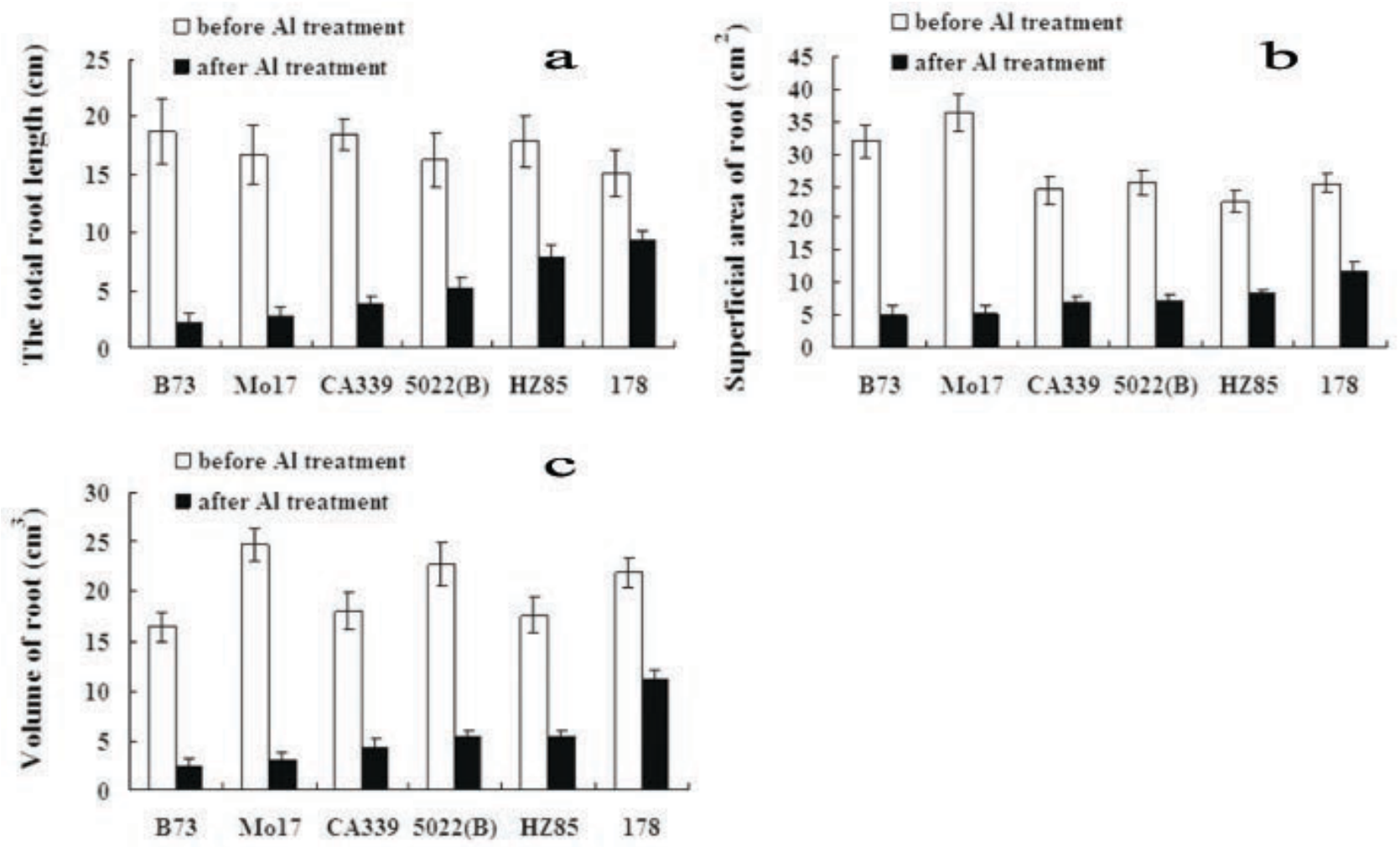

The six maize cultivars 178, HZ85, CA339, 5022(B), B73, and Mo17 were assessed by digital scanning of the total root length (A), superficial area (B), and volume (C) after treatment with $60 \mu \mathrm{mol}$ aluminum for three days. Vertical bars indicate the SD of the mean values.

Figure 1. Digital scanning analysis of the total root system

\subsection{Evaluation of the Root Biomass of Six Maize Cultivars Exposed to Al}

The biomass of the root can reflect its development and growth. When subjected to Al stress, Al-tolerant cultivars proliferate more roots than do Al-sensitive cultivars [34]. Root biomass can be described by the dry and fresh weights of whole root systems. After the Al stress in this experiment, both the dry and fresh weights of all six cultivars significantly decreased to different extents (Fig. 2a, b). For the Al-tolerant cultivars HZ85 and 178, the fresh root weights shrank to $71.76 \%$ and $75.07 \%$ and the coherent dry weights decreased to $71.77 \%$ and $76.63 \%$ of the control, respectively. In contrast, fresh weight decreased in the Al-sensitive cultivars B 73 and Mo17 by $62.19 \%$ and $66.71 \%$, respectively, and dry weight by $49.59 \%$ and $62.35 \%$, respectively, due to $\mathrm{Al}$ stress. For the moderately Al-tolerant cultivars CA339 and 5022(B), Al stress inhibited dry weight by roughly $45 \%$ and fresh weight by approximately $55 \%$ (Fig. 2). The correlation coefficient (r) between the RRG and the fresh root and dry root was up to 0.84 and 0.61 respectively. This result also suggested that root biomass was suitable for rating the $\mathrm{Al}$ sensitivity of genotypes and was in good agreement with the RRG measurements.
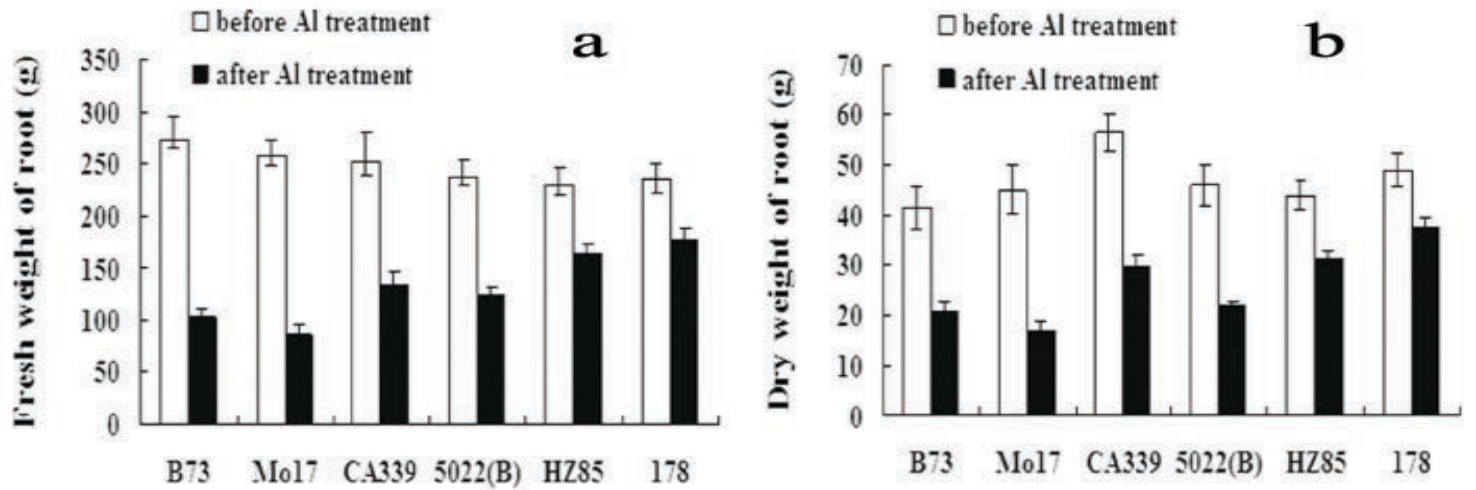

The fresh (A) and dry (B) weights of the six maize cultivars 178, HZ85, CA339, 5022(B), B73, and Mo17 were measured after treatment with $60 \mu$ mol aluminum for three days. Vertical bars indicate the SD of the mean values.

Figure 2. Measurement of the root biomass 


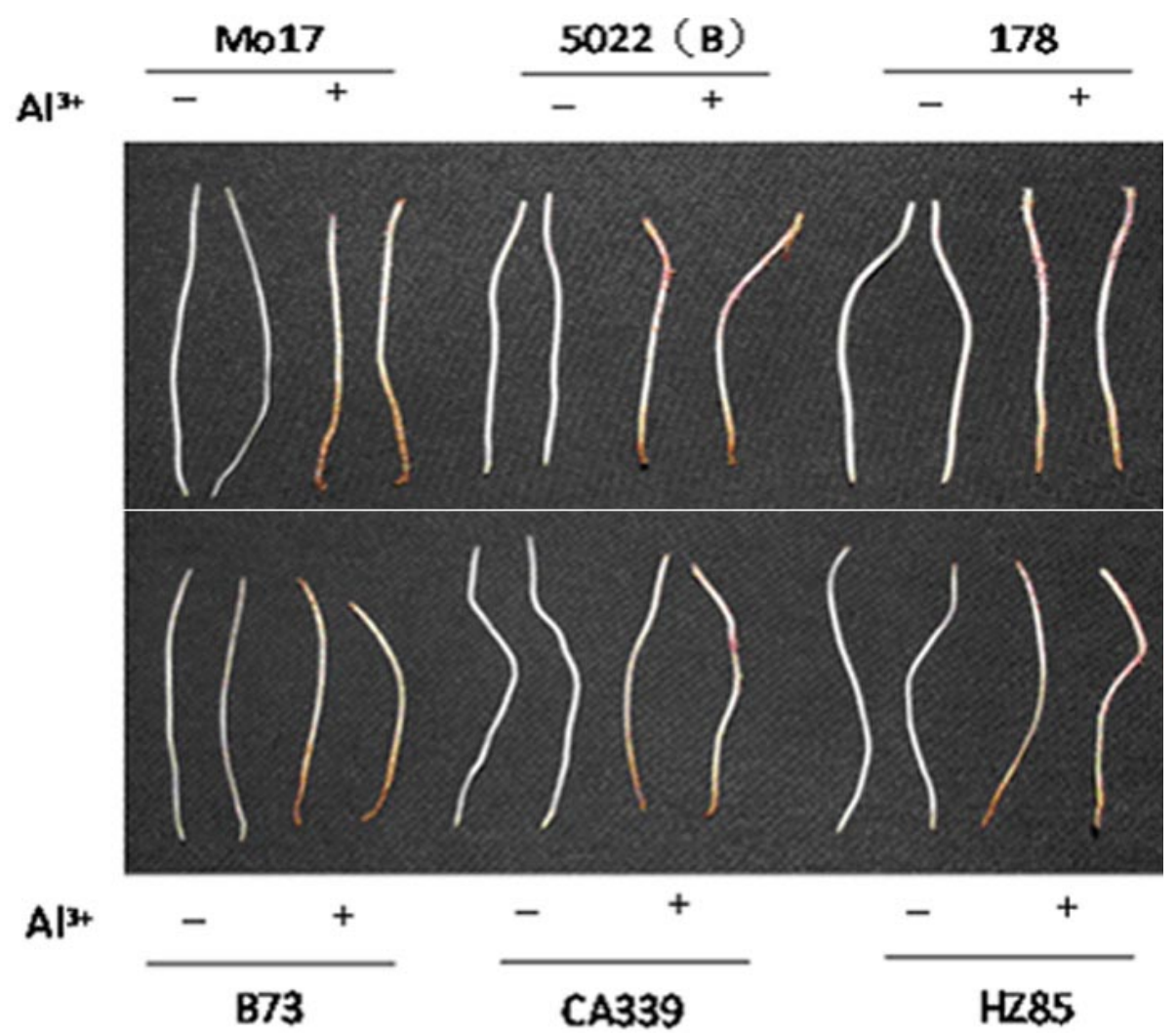

Root fragments of the six maize cultivars 178, HZ85, CA339, 5022(B), B73, and Mo17 were stained in hematoxylin solution after three days of exposure to $60 \mu \mathrm{mol}$ aluminum.

Figure 3. Hematoxylin staining patterns and staining intensity

\subsection{Estimation of Al Tolerance of Maize Cultivars by Hematoxylin Staining}

A rapid method for evaluating $\mathrm{Al}$ tolerance using hematoxylin staining has been developed based on the formation of a colored complex between hematoxylin and root-bound Al. The color intensity of stained root apices subjected to Al stress can be directly measured, as susceptible genotypes tend to accumulate higher amounts of $\mathrm{Al}$ in their root tissues. These variations have been assessed as stained, unstained, and partially stained to represent Al-sensitive, tolerant, and intermediate genotypes, respectively[24]. Hematoxylin staining analysis showed that B73 and Mo17 exhibited the most intense root staining, whereas HZ85 and 178 showed the least intense staining. CA339 and 5022(B) were moderately stained compared with the other lines (Fig. 3). These results clearly indicated that hematoxylin staining was indeed able to discriminate the $\mathrm{Al}$ sensitivity of maize genotypes early in root development.

\section{Discussion}

A rapid and reliable screening method is necessary for crop breeders to effectively select Al-tolerant germplasm. Numerous methods and phenotypic indexes have been developed based on the physiological responses of plants subjected to $\mathrm{Al}[12,13,35]$. Among these methods, $\mathrm{RRG}$ is the most widely used phenotypic index for rating $\mathrm{Al}$ tolerance in cereals $[19,31,32]$. For example, Khatiwada [18] classified 62 traditional rice cultivars grown on lowland acidic sulfate soils in Asia and West Africa into three different groups according to the RRG of the longest root when exposed to a nutrient solution containing $30 \mathrm{ppm} \mathrm{Al}$ for 14 days. Using a similar approach, Piñeros [32] ranked six maize lines into three main categories according to the RRG of the seminal root after growth in a full nutrient solution containing an effective $40 \mu \mathrm{mol} \mathrm{Al}^{3+}$ for 3 days: highly Al-tolerant (RRG $>80 \%)$, moderately Al-tolerant $(55 \%<$ $\mathrm{RRG} \leq 80 \%$ ), and $\mathrm{Al}$ sensitive ( $\mathrm{RRG} \leq 55 \%$ ). In the current study, , we classified 141 maize germplasm lines into three groups according to the RRG of the longest root after exposure to $60 \mu \mathrm{mol} \mathrm{Al} \mathrm{for} 3$ days (Table 1). The RRG levels used to classify the maize lines were significantly higher than those used for the corresponding categories in the previous study. Furthermore, among the 22 Al-sensitive maize lines with RRG $<10 \%$, Duo Huang 29 and K12 had the lowest values $(R R G=0.0227)$ and exhibited the highest sensitivity to Al toxicity. This result showed that the root growth of some maize lines was seriously inhibited in 60 $\mu \mathrm{mol} \mathrm{Al}$ solution and those roots could not further develop beyond this threshold of $\mathrm{Al}$ concentration.

Multiple factors may have caused the low RRG values in the current study. Generally, different genotypes vary in tolerance to certain stress environments. The six maize lines in Piñeros's study were chosen based on their different 
genotypic origins and ecological zones, while most of the 141 maize germplasm lines in this study were collected from the main maize production regions of China, which have no acidic soils or are not typically acidic. Therefore, the most tolerant cultivars in this study, such as 178 , had relatively lower RRG values, while Cateto-Colombia, which originated from a tropical zone rich in acidic soil, exhibited the strongest $\mathrm{Al}$ tolerance and the highest RRG value. The optimal Al concentration employed in any given study depends on the general tolerance level of the genotypes screened and whether complete growth inhibition is desired[9]. In this study, although some sensitive maize lines possessed low RRG levels, $60 \mu \mathrm{mol} \mathrm{Al}{ }^{3+}$ did not completely inhibit root growth and could be used to screen and classify the 141 maize genotypes for Al tolerance. The low RRG values could have been increased by reducing $\mathrm{Al}^{3+}$ concentration, but the evaluation of maize genotypes would have been unaffected. In addition, the seedlings subjected to $\mathrm{Al}$ stress were supplied only with $60 \mu \mathrm{mol} \mathrm{AlCl}_{3}$ together with $200 \mu \mathrm{mol} \mathrm{CaCl}_{2}$ in the current study, whereas in Piñeros's experiment, the treated seedlings were grown in a full nutrition solution with $40 \mu \mathrm{mol}$ effective $\mathrm{Al}^{3+}$. The extra nutrition in Piñeros's test may have caused more vigorous root growth even under $\mathrm{Al}$ stress, as reflected by the higher RRG values in that study. Moreover, some ions in a full nutrition solution, such as phosphate, calcium, and magnesium, can interact with $\mathrm{Al}$ to alleviate $\mathrm{Al}$ toxicity [7, 36]. A simple solution only containing Al may somehow affect plant development even if the nutrition satisfied the seedlings' developmental requirements, thereby making the seedlings more sensitive to $\mathrm{Al}$ toxicity.

The RRG of the longest root has been widely used as a suitable phenotypic index for assessing $\mathrm{Al}$ tolerance in cereal seedlings cultivated in nutrient solution. Nevertheless, this value should not be used as the single assessment criterion, as it may be misleading in genotypes that accumulate high amounts of $\mathrm{Al}$ in the aerial part of the plant or manifest $\mathrm{Al}$ tolerance at the adult stage $[6,36,37]$. Famoso et al. [31], for example, found that RRG of the longest root was not the best predictor of $\mathrm{Al}$ tolerance in rice. Therefore, the six representative maize lines HZ85, 178, CA339, 5022 (B), $\mathrm{B} 73$, and Mo17, which belonged to different Al tolerance groups, were used to further investigate the sensitivity to $\mathrm{Al}$ stress with other methods.

Previous reports in maize, wheat, sorghum, soybean, sugarcane, and tobacco have indicated that more severe inhibition occurs in lateral roots than in the longest root in Al-sensitive genotypes [22, 23, 38, 39]. Furthermore, Famoso et al. [31] found that the RRG of the longest root was not a good proxy for the total root system in evaluating the $\mathrm{Al}$ tolerance of genotypes. A genotype may therefore appear tolerant based on the longest root measurement while actually exhibiting overall root growth inhibition. Intriguingly, based on the digital scanning data of the total root length, superficial area, and volume, the six representative cultivars in this study were assigned into the same groups as those previous assigned by the RRG of the longest root (Fig. 1, Table 1).

In addition to the proxy mentioned above, comparing the root biomass of plants in the presence or absence of $\mathrm{Al}$ is another common criterion used to measure Al toxicity [23]. Root biomass (fresh and dry weights) measurements of the six representative maize cultivars after short-term culturing again classified the genotypes into the previously assigned groups (Fig. 2).

Hematoxylin staining, a rapid and simple method, was also used to evaluate the $\mathrm{Al}$ stress phenotypes of maize seedlings in the current study. Hematoxylin, a dye commonly used in cytogenetic studies, has also been employed as a quick, nondestructive way of assessing plant genotypes for Al tolerance [24, 25, 40-42]. Berezovskii et al. [24] recommended a qualitative scale to rate different genotypes for $\mathrm{Al}$ tolerance based on how completely their roots were stained. The classification of the six maize lines according to hematoxylin staining was in consensus with the results for the other methods (Figs. 1-3, Table 1). Similar results have also been reported for Canadian cultivars by Zale and Briggs [43]. These results showed a potential relationship between hematoxylin ratings and root growth measurements in cereals.

A long evolutionary history of exposure to $\mathrm{Al}$ is likely to favor the development of highly adapted genotypes with polygenic control of resistance, because $\mathrm{Al}$ resistance can be modified by a considerable number of genes $[44,45]$. The molecular mechanisms of $\mathrm{Al}$ tolerance have been gradually unveiled by the great advances recently made in research on higher plants [46, 47]. However, reports regarding Al-tolerant maize germplasm and molecular explorations of Al tolerance have been comparatively limited. Due to the rapid spread of acidic soils, the exploration and application of $\mathrm{Al}$ tolerance genes in crop breeding, molecular marker-assisted selection, and genetic engineering are ongoing.

\section{Conclusions}

Al toxicity is the main limiting factor for maize root elongation in acidic soils. Several methods have been developed to classify differences in the sensitivity to Al exposure of plant germplasm. The current study classified maize germplasm lines using four approaches based on $\mathrm{Al}$ stress responses. A total of 141 maize germplasm lines were classified into three groups based on the RRG of the longest root. Among these lines, 178 and HZ85 were the most tolerant maize cultivars. Two representative lines from each of the three different groups were then further evaluated. Similar group rankings were obtained by measuring the total root length, volume, and superficial area, taking fresh and dry weights, and hematoxylin staining. In conclusion, multiple criteria may be flexibly combined to rationally classify the Al tolerance of different maize genotypes. 


\section{Acknowledgements}

This work was supported by the National Program on Key Basic Research Project of China (973 Program, 2014CB138705), Ph.D. Programs Foundation of Ministry of Education of China (1.20125103110011), grants from National Natural Science Foundation of China (No.30800687 and No.31071434), Scientific Research Foundation for the Returned Overseas Chinese Scholars, State Education, the National Key Science and Technology Special Project (2013ZX08003-005), the National High Technology Research and Development Program of China (2012AA101104).

Liming $\mathrm{Xu}, \mathrm{Wu}$ Liu, These authors contributed equally to this study.

\section{REFERENCES}

[1] H. Von Uexküll, E. Mutert, Global extent, development and economic impact of acid soils, Plant and soil, 171 (1995) $1-15$.

[2] Y. Xiong, Q. Li, Soils in China, Science Press, Beijing, (1987) 529-533.

[3] J. Guo, X. Liu, Y. Zhang, J. Shen, W. Han, W. Zhang, P. Christie, K. Goulding, P. Vitousek, F. Zhang, Significant acidification in major Chinese croplands, Science, 327 (2010) 1008-1010.

[4] D.A. Samac, M. Tesfaye, Plant improvement for tolerance to aluminum in acid soils-a review, Plant Cell, Tissue and Organ Culture, 75 (2003) 189-207.

[5] C. Foy, R.t. Chaney, M. White, The physiology of metal toxicity in plants, Annual Review of Plant Physiology, 29 (1978) 511-566.

[6] C. Foy, C. Peterson, Acid soil tolerances of wheat lines selected for high grain protein content, Journal of plant nutrition, 17 (1994) 377-400.

[7] C.D. Foy, Plant adaptation to acid, aluminum - toxic soils, Communications in Soil Science \& Plant Analysis, 19 (1988) 959-987.

[8] L.V. Kochian, Cellular mechanisms of aluminum toxicity and resistance in plants, Annual review of plant biology, 46 (1995) 237-260.

[9] M. Sasaki, Y. Yamamoto, H. Matsumoto, Lignin deposition induced by aluminum in wheat (Triticum aestivum) roots, Physiologia Plantarum, 96 (1996) 193-198.

[10] S.-F. Dai, Z.-H. Yan, D.-C. Liu, L.-Q. Zhang, Y.-M. Wei, Y.-L. Zheng, Evaluation on chinese bread wheat landraces for low $\mathrm{pH}$ and aluminum tolerance using hydroponic screening, Agricultural Sciences in China, 8 (2009) 285-292.

[11] L. Shuman, E. Ramseur, D. Wilson, Video image method compared to a hand method for determining root lengths, Journal of plant nutrition, 16 (1993) 563-571.

[12] J.-p. Wang, H. Raman, G.-p. Zhang, N. Mendham, M.-x. Zhou,
Aluminium tolerance in barley (Hordeum vulgare L.): physiological mechanisms, genetics and screening methods, Journal of Zhejiang University SCIENCE B, 7 (2006) 769-787.

[13] F. Gallardo, F. Borie, M. Alvear, E. von Baer, Evaluation of aluminum tolerance of three barley cultivars by two short-term screening methods and field experiments, Soil science and plant nutrition, 45 (1999) 713-719.

[14] H. Raman, J. Moroni, K. Sato, B. Read, B. Scott, Identification of AFLP and microsatellite markers linked with an aluminium tolerance gene in barley (Hordeum vulgare L.), Theoretical and Applied Genetics, 105 (2002) 458-464.

[15] B.F. Carver, J.D. Ownby, Acid soil tolerance in wheat, advances in Agronomy, 54 (1995) 117-173.

[16] T. Wagatsuma, Y. Ezoe, Effect of $\mathrm{pH}$ on ionic species of aluminum in medium and on aluminum toxicity under solution culture, Soil science and plant nutrition, 31 (1985) 547-561.

[17] V. Coronel, S. Akita, S. Yoshida, Aluminium toxicity tolerance in rice (Oryza sativa) seedlings, in: Plant nutrition-physiology and applications, Springer, 1990, pp. 357-363.

[18] S.P. Khatiwada, D. Senadhira, A. Carpena, R. Zeigler, P. Fernandez, Variability and genetics of tolerance for aluminum toxicity in rice (Oryza sativa L.), Theoretical and Applied Genetics, 93 (1996) 738-744.

[19] P. Wu, B. Zhao, J. Yan, A. Luo, Y. Wu, D. Senadihra, Genetic control of seedling tolerance to aluminum toxicity in rice, Euphytica, 97 (1997) 289-293.

[20] X.F. Li, J.F. Ma, H. Matsumoto, Pattern of aluminum-induced secretion of organic acids differs between rye and wheat, Plant Physiol, 123 (2000) 1537-1544.

[21] L. Shuman, D. Wilson, R. Duncan, Screening wheat and sorghum cultivars for aluminum sensitivity at low aluminum levels, Journal of plant nutrition, 16 (1993) 2383-2395.

[22] S. Hetherington, C. Asher, F. Blamey, Comparative tolerance of sugarcane, navybean, soybean and maize to aluminium toxicity, Crop and Pasture Science, 39 (1988) 171-176.

[23] J.F. Ma, S. Nagao, K. Sato, H. Ito, J. Furukawa, K. Takeda, Molecular mapping of a gene responsible for Al - activated secretion of citrate in barley, Journal of experimental botany, 55 (2004) 1335-1341.

[24] M.E. Berezovskii, [Method of staining of semi-thin sections with hematoxylin-eosin], Arkhiv patologii, 40 (1978) 69-70.

[25] B.F. Carver, W.P. Inskeep, N.P. Wilson, R.L. Westerman, Seedling tolerance to aluminum toxicity in hard red winter wheat germplasm, Crop science, 28 (1988) 463-467.

[26] H. Takagi, H. Namai, K. Murakami, Evaluation of the hematoxylin staining method for detecting wheat tolerance to aluminium, Japanese Journal of Breeding, (1981).

[27] N.A. Ruiz-Torres, B.F. Carver, Genetic expression of aluminum tolerance in hard red winter wheat, Cereal Research Communications, (1992) 233-240.

[28] L. Bona, R. Wright, V. Baligar, J. Matuz, Screening wheat and other small grains for acid soil tolerance, Landscape and Urban Planning, 27 (1993) 175-178. 
[29] J. Fisher, B. Scott, Response to selection for aluminium tolerance, Priorities in Soil/Plant Relations Research for Plant Production. Univ. of Sydney, Australia, (1987) 135-137.

[30] B. Carver, W. Whitmore, E. Smith, L. Bona, Registration of four aluminum-tolerant winter wheat germplasms and two susceptible near-isolines, Crop science, 33 (1993) 1113-1114.

[31] A.N. Famoso, R.T. Clark, J.E. Shaff, E. Craft, S.R. McCouch, L.V. Kochian, Development of a novel aluminum tolerance phenotyping platform used for comparisons of cereal aluminum tolerance and investigations into rice aluminum tolerance mechanisms, Plant Physiology, 153 (2010) 1678-1691.

[32] M.A. Piñeros, J.E. Shaff, H.S. Manslank, V.M.C. Alves, L.V. Kochian, Aluminum resistance in maize cannot be solely explained by root organic acid exudation. A comparative physiological study, Plant Physiology, 137 (2005) 231-241.

[33] G. Cançado, L. Loguercio, P. Martins, S. Parentoni, E. Paiva, A. Borém, M. Lopes, Hematoxylin staining as a phenotypic index for aluminum tolerance selection in tropical maize (Zea mays L.), Theoretical and Applied Genetics, 99 (1999) 747-754.

[34] C. Tang, E. Diatloff, Z. Rengel, B. McGann, Growth response to subsurface soil acidity of wheat genotypes differing in aluminium tolerance, Plant and soil, 236 (2001) 1-10.

[35] B.F. Carver, J.D. Ownby, Acid soil tolerance in wheat, Advances in agronomy (USA), (1995).

[36] N. Massot, C. Poschenrieder, J. Barcelo, Differential response of three bean (Phaseolus vulgaris) cultivars to aluminium, Acta botanica neerlandica, 41 (1992) 293-298.

[37] M. Moustakas, G. Ouzounidou, R. Lannoye, Rapid screening for aluminum tolerance in cereals by use of the chlorophyll fluorescence test, Plant breeding, 111 (1993) 343-346.

[38] V.N. Bushamuka, R.W. Zobel, Maize and soybean tap, basal, and lateral root responses to a stratified acid, aluminum-toxic soil, Crop science, 38 (1998) 416-421.

[39] I.R. Silva, T.J. Smyth, C.D. Raper, T.E. Carter, T.W. Rufty, Differential aluminum tolerance in soybean: an evaluation of the role of organic acids, Physiologia Plantarum, 112 (2001) 200-210.

[40] E. Delhaize, S. Craig, C.D. Beaton, R.J. Bennet, V.C. Jagadish, P.J. Randall, Aluminum tolerance in wheat (Triticum aestivum L.)(I. Uptake and distribution of aluminum in root apices), Plant Physiology, 103 (1993) 685-693.

[41] M. Rincón, R.A. Gonzales, Aluminum partitioning in intact roots of aluminum-tolerant and aluminum-sensitive wheat (Triticum aestivum L.) cultivars, Plant physiology, 99 (1992) 1021-1028.

[42] T. Wagatsuma, S. Ishikawa, H. Obata, K. Tawaraya, S. Katohda, Plasma membrane of younger and outer cells is the primary specific site for aluminium toxicity in roots, in: Plant-Soil Interactions at Low $\mathrm{pH}$ : Principles and Management, Springer, 1995, pp. 271-278.

[43] J.M. Zale, K.G. Briggs, Aluminum tolerance in Canadian spring wheats, Communications in Soil Science \& Plant Analysis, 19 (1988) 1259-1272.

[44] P.B. Larsen, C.-Y. Tai, L.V. Kochian, S.H. Howell, Arabidopsis mutants with increased sensitivity to aluminum, Plant physiology, 110 (1996) 743-751.

[45] E. Schott, R. Gardner, Aluminum-sensitive mutants of Saccharomyces cerevisiae, Molecular and General Genetics MGG, 254 (1997) 63-72.

[46] J.F. Ma, Role of organic acids in detoxification of aluminum in higher plants, Plant and Cell Physiology, 41 (2000) 383-390.

[47] L.V. Kochian, O.A. Hoekenga, M.A. Piñeros, How do crop plants tolerate acid soils? Mechanisms of aluminum tolerance and phosphorous efficiency, Annu. Rev. Plant Biol., 55 (2004) 459-493. 